\title{
New and traditional relay protection algorithms integration in 6-35 kV distribution network
}

\author{
Mikhail Sharygin ${ }^{1}$, Vladimir Vukolov ${ }^{1}$, Mikhail Obalin², Anton Petrov ${ }^{3, *}$ \\ ${ }^{1}$ R. E. Alekseev Nizhnii Novgorod State Technical University, 603950, Minin Str. 24, Nizhnii Novgorod, Russia \\ ${ }^{2} J S C$ “SO UPS”, Nizhny Novgorod branch, 603034, Shlisselburgskaya Str, 29, Nizhnii Novgorod, Russia \\ ${ }^{3}$ JSC "NIPOM", advanced development department, 603140, Lenin Ave., 20, Nizhnii Novgorod, Russia
}

\begin{abstract}
We conducted an applicability analysis of both modern and prospective relay protection types in future $6-35 \mathrm{kV}$ field circuits. We demonstrated the advantages of using new differential-logic and multi-parameter relay protection algorithms, as well as the methods for relay protection tripping parameters calculation. We developed an integration scheme for existing and prospective relay protections types to increase the sensitivity and speed of the relay protection system for SmartGrid. We suggested the main stages of implementing new relay protection types.
\end{abstract}

\section{Introduction}

Electrical power networks in the Russian Federation are undergoing a large-scale digital transformation. Nowadays, regulatory industry requirements provide for developing new algorithms for adaptive relay protection (RP) and for designing digital substations as highly automated low-maintenance substantions with operational settings switching through automated relay protection and automatic equipment workstations. A digital electrical power network will imply the most automated intelligent control of the operating mode and all component without human intervention.

The future transition of 6-35 kV circuits into a new qualitative state of SmartGrid [1] implies the field circuit structure complication, their permanent reconfiguration, the availability of distributed generation, and a stochastic load. These factors require a new relay protection system with increased speed, sensitivity, and continuous automatic adaptation to changes in the field circuit $[2,3]$. However, there is no holistic view of the future of the relay protection system yet.

\section{Developing an interaction scheme for traditional and perspective relay protection types}

Traditional requirements for a relay protection system (selectivity, tripping speed, sensitivity, and reliability) well describe its technical perfection, and, at the same time, they completely abstract away from the specific implementations of protection devices and algorithms and being fundamental in the development of new protection types.

The relay protection system may be organized by a two-level scheme with differentiation based on selectivity. The first level includes high-speed protection of absolute selectivity without a backup zone. The selectivity of such protections is ensured by configured the operation parameters. The second level is represented by the relative selectivity protection with backup protection zones. Selectivity of such protections is ensured by stepped detuning of the tripping time.

Two independent levels will ensure compatibility of new protection types with traditional devices. It is possible to use different relay protection algorithms: new and traditional, centralized or decentralized, as well as mixed-type protections.

The first level of relay protection can contain traditional high-speed protection (without time delay) or protection based on new principles (differential-logic protection using the IEC 61850 communication network [4]). Despite its obvious advantages (instant selective cutting off of faults), the first protection level has the following drawbacks (one or several at once):

- does not allow full redundancy of tripping due to unrecognizable failures of protection or switches;

- dependence on communication systems and the operation of adjacent relay protection devices;

- can cover only part of the object;

- may not detect all damage types.

In this regard, the first protection level should be supplemented by the second level, which includes protection with relative selectivity, triggered with a time delay after the failure of the first level protection. For full redundancy, the second protection level should selectively disconnect all calculated faults, based only on local measurements at the its installation location, even without using communication systems and signals from adjacent devices. The presence of a communication system and the algorithms complexity will increase the speed and second-level protection sensitivity, while strictly observing selectivity. In the communication

\footnotetext{
* Corresponding author: petrov85@inbox.ru
} 
system absence, for example, in conditions of poorly responsible distribution networks, it is possible to use only the second level of protection: traditional or new, for example, multiparametric protection, based on statistical principles $[5,6]$.

Let us consider the effectiveness of the suggested configuration of the relay protection system in various cases: with or without an information network and with various types of protection installed in the network.

The absence of an information network will not allow for creating the first relay protection level using differential or differential logic-protections; therefore, the network will only be protected by step protections, that may be either traditional (overcurrent protection or distance protection) or perspective multi-parameter step relative selectivity protection. This relay protection is a generalization of distance and overcurrent protections. If measuring only the current modulus, the protection is reduced to overcurrent protection, when measuring resistance only, to distance protection [7]. However, the triggering element of a multi-parameter relay protection provides a greater sensitivity due to a mode parameters choice that are more informative than current and resistance. If relay protection is designed with a multiparameter protection, power cutoff is guaranteed to be no less fast and sensitive than by distance or overcurrent protection due to the greater technical perfection of multi-parameter protection and its adaptive capabilities. Backing up is also designed with great sensitivity and speed.

If there is an information network between substations, the main protection of the field circuit shall be definitely designed to be as fast and sensitive as possible, using differential or similar principle. Differential-logic protection is capable of detecting individual relay protection devices or instrument transformers failures and to back up them. Also this protection will be redundantly backed by protection steps of relative selectivity (instant and slow steps).

We shall bear in mind that the information network may fail (partially or completely); moreover, its failures can be accompanied by short circuits in the electrical power network. For such cases, a backup relay protection of the second level shall be provided, tripping as quickly, sensitively, and selectively as possible, based on the minimum amount of information from the local measuring feeder converters without using communication systems and without signals from adjacent devices.

In the event of an information network failure, the protection system is transformed into a traditional distributed relay protection system for 6-35 kV networks: upon a failure of the differential protection, the electrical network will be protected only by step protections that are tripped instantly or with a time delay (at the end of the protected facility). Fault tripping backup will only be realized by distance protection or overcurrent protection steps on adjacent feeders.

In the event of failure of individual instrument transformers (current transformers, voltage transformers) or feeder relay protection devices, its faults will be cut off with a time delay and non-selectively by adjacent feeders from their slow steps of distance or overcurrent protection. A failure of the feeder switch leads to similar results.

Therefore, an relay protection system based on traditional high-sensitivity differential protection and overcurrent protection can be quite effective, but will have some drawbacks:

- a full differential protection failure even with partial failures of the information network;

- impossibility of quick adapting the current network configuration and its mode, as calculation of configuration and adjustment of traditional protections is done not automatically, but manually;

- low sensitivity and low protection speed due to the need to detune them out of all kinds of distribution network modes having a complex multi-loop topology with several sources operating in parallel;

- any failure in the relay protection system will surely lead to a slowdown of fault trips in one or more protection zones.

These disadvantages can be largely eliminated through the use of new relay protection types (Fig. 1):

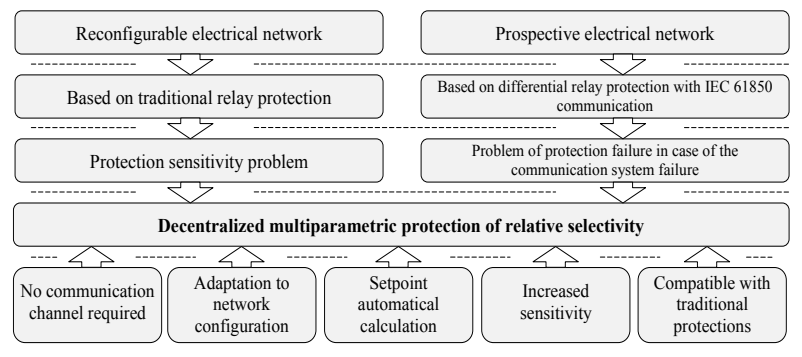

Fig. 1. Solving problems of sensitivity and relay protection failure in reconfigurable field circuits and prospective microgrids

- a full failure of the differential-logic protection will occur only in the information network full failure case;

- upon the information network failure, the multiparameter protection will lose only the ability to adapt to the operation mode (it will switch to a single versatile set of settings suitable for all network modes), but its sensitivity and speed will still be higher than those of traditional distance and overcurrent protections in all zones due a greater technical perfection;

- in case of the information network certain parts failure, the differential-logic protection will fail partially, rather than completely: as a result of changing protection zones, it will be capable of instant, but partially nonselective cutoff of faults (in the absence of locking, the entire network part that has lost its communication system will be cut off, if a fault occurs therein). A multiparameter protection will repeatedly back up tripping, remaining completely selective even in the zone of the failed information network (similar to distance and overcurrent protection, but with a higher sensitivity and speed);

- in case of a failure of individual feeder measuring converters, a differential-logic protection will fail only partially: in case of short-circuit in zones adjacent to a failed instrument transformer and in the absence of locking, it will instantly cut off the nearest feeders with 
nonfaulty meashurement transformers. Multi-parameter feeder protection will also fail partially, as the length of its measurement vector will decrease due to the loss of information coming from a failed devices, but the protection will continue to selectively function due to the remaining measurements, with reduced sensitivity and speed. Note that, in this case, a traditional protection fail completely.

Upon the relay protection or feeder switch failure, a differential-logic protection will also partially fail in case of short circuit in the zones adjacent to the failed feeder and, in the absence of locking, will cut off the nearest nonfaulty feeders. The multi-parameter protection of the failed feeder will be fully inoperative, and backing up will be ensured only by slow steps of adjacent multiparameter second-level protection.

In any case, the performance of a protection system based on new algorithms is higher than when using traditional relay protection types, due to its greater technical perfection.

\section{Emergency mode detection efficiency}

Let us compare the probability of detecting emergency modes by various protections. Due to their operating principle, differential protections are capable of detecting any fault in their operation zone, therefore, detecting probability of an emergency mode by them is close to unity. Time-delayed step protections reliably cover the entire protected facility, therefore, fault detecting probability by them is also close to unity. It is interesting to compare step protections without time delay, that protect only part of a facility and controled by various electrical power network operation mode parameters sets.

As controlled parameters, we will use: current $I$, voltage $U$, angle $\varphi$ between current and voltage, impedance $Z$, complex impedance $R+j X$.

The protection operation performance is checked using a simulation of normal and emergency modes for a power transmission line as shown in Fig. 2. Relay protection will detect faults in the power transmission line, while it should not be triggered in case of a short circuits in outgoing feeders as well as in the modes of starting of an asynchronous load and in normal modes. The fault detecting probability is described as the share of the total faults number in the protected transmission line, that are detected by the relay protection [8].

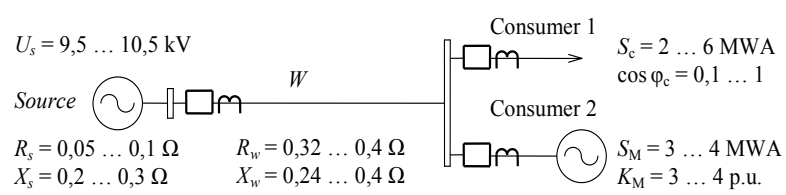

Fig. 3. Parameters for modes simulation

A comparison of the probabilities of detecting faults by protections that control different sets of parameters is given in Table 1.

The table shows that an increase in the number of controlled parameters has a positive effect on the detection efficiency by the failures protection in an electrical power network [9]. The intensity the controlled parameter changes in the event of a fault, the more effectively the modes are recognized [10].

Table 1. Comparison of the probabilities of detecting faults by protections

\begin{tabular}{|l|c|c|c|c|c|}
\hline \multirow{2}{*}{ Recognition factors } & \multicolumn{5}{|c|}{ Controlled parameters } \\
\cline { 3 - 6 } & $\boldsymbol{I}$ & $\boldsymbol{I}, \boldsymbol{U}$ & $\boldsymbol{I}, \boldsymbol{U}, \boldsymbol{Z}$ & $\boldsymbol{Z}$ & $\boldsymbol{R}+\boldsymbol{j} \boldsymbol{X}$ \\
\hline $\begin{array}{l}\text { Probability of short } \\
\text { circuit recognition in }\end{array}$ & 0,60 & 0,80 & 0,873 & 0,69 & 0,898 \\
$\begin{array}{l}\text { a power transmission } \\
\text { line by an instant step }\end{array}$ & & & & & \\
\hline
\end{tabular}

\section{Continuous automatic adaptation of relay protection tripping parameters}

We can additionally increase the relay protection operation speed and sensitivity due to constant automatically relay protection tripping parameters (settings) adaptation to the network configuration and its loads. This can be achieved using the new method of automatic coordination and relay protection parameters calculation. The method is applicable to any topology networks up to $220 \mathrm{kV}$ with traditional step relay protection types and to new multi-parameter protection.

The relay protection setpoints automatically calculation algorithm seeks to ensure the selectivity of all network protections with unconditional detuning out of all specified permissible modes. Protection settings are determined based on generally accepted requirements and norms according to conditions corresponding to typical "extreme" modes of an electrical power network, therefore, the developed method does not contradict the traditional theory of calculating relative selectivity relay protection, but develops and supplements it. An automatically calculated overcurrent protection will be as fast and sensitive as one calculated manually without errors.

If we need to increase the protection operation speed and sensitivity, we shall replace the measured value with a new, more informative one. The developed automatical relay protection method will be also applicable for multiparametrical protection, whereas manual calculation of new protections will require developing new method and personnel training.

To test the automatic method for coordinating and calculating the tripping parameters, we have created the prototype of a client-server software system, the tests on which have confirmed the method efficiency and high performance.

A qualitative change in the basic requirements for relay protection devices using the prospective (relatively traditional) protection is given in Table 2 .

The prospective protection sensitivity is enhanced by increasing the number of monitored parameters and the use of settings automatical calculation, taking into account network topology and power flows. Technical perfection and adaptability are improved through an information exchange between an electrical power network nodes. Increasing the operation area will allow the faulty component to be cut off by a step with a 
shorter time delay, thus reducing the average protection tripping time.

Table 2. Change in the protection performance and adaptability when using prospective protections

\begin{tabular}{|c|c|c|c|c|c|}
\hline 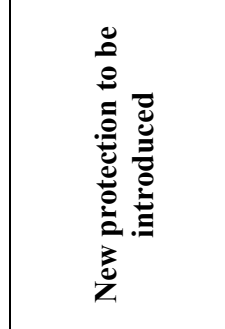 & 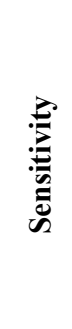 & 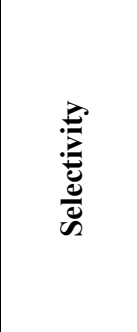 & क्ष & 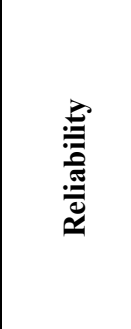 & 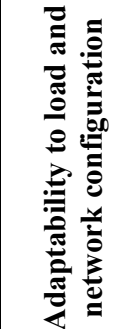 \\
\hline $\begin{array}{l}\text { Differential- } \\
\text { logic relay } \\
\text { protection only } \\
\end{array}$ & +++ & Preserved & +++ & - & +++ \\
\hline $\begin{array}{l}\text { Multi-parameter } \\
\text { relay protection } \\
\text { only }\end{array}$ & ++ & Preserved & + & Preserved & Preserved \\
\hline $\begin{array}{l}\text { Automatic } \\
\text { calculation of } \\
\text { settings only }\end{array}$ & +++ & Preserved & ++ & + & +++ \\
\hline $\begin{array}{l}\text { All types of } \\
\text { protection, } \\
\text { including } \\
\text { automatically } \\
\text { calculation } \\
\end{array}$ & +++ & Preserved & +++ & + & +++ \\
\hline
\end{tabular}

Note: Plus indicates an increase in the parameter, minus, a decrease in the indicator; the number of pluses/minuses, the level of increase/decrease in the parameter.

The prospective protections can be implemented on the existing element base, on which modern microprocessor protections are currently built. And since multi-parameter protections can operate even upon a failure of measuring converters, the reliability of such protection system will increase.

\section{Main stages of introducing new relay protection types}

In the adopted scheme of existing and prospective relay protection types, it is advisable to develop the protection network system in four conventional stages (Table 3 ).

The first stage of the relay protection development involves the communication channels organization, which will allow to implement differential protection network (main protection). Multi-parameter protection is used as a backup protection. The first protection implementation stage results in:

- increased performance and sensitivity of the main protection;

- the possibility of automatically relay protection setpoints calculation using will increase the protection technical perfection and power supply reliability by adapting the protection settings to the power grid topology.

In the second development stage traditional protection advisable to replace by the differential-logic (main protection) and multiparametrical (level 2):
- differential-logic protection can be implemented only in the presence of a communication network according to IEC 61850;

- multiparametric protection will allow you to increase sensitivity due to the use of multiple measurements.

At the third stage, the technology for automatic calculation of protection settings will allow organizing a fully automatic relay protection system in the Plug \& Play format and self-adaptation (automatic parameterization of equipment connected to the electric network).

Fourth stage involves the use of network modes automatic control, taking into account the costs and damages of consumers and energy companies, part of which is a fully automatic relay protection system.

Table 3. Main stages of introducing new relay protection types

\begin{tabular}{|c|c|c|c|c|c|}
\hline 总 & 苞: & 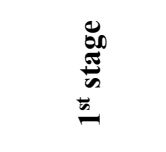 & 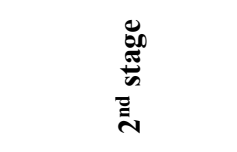 & 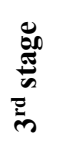 & 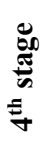 \\
\hline 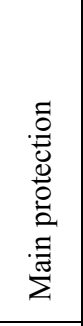 & 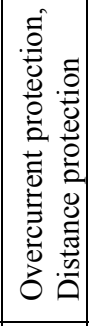 & $\begin{array}{l}\text { Differential } \\
\text { protection }\end{array}$ & $\begin{array}{l}\text { Differential-logic } \\
\text { protection using } \\
\text { the IEC } 61850 \\
\text { communication } \\
\text { network }\end{array}$ & 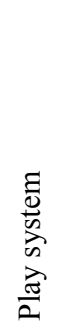 & $\vec{\Xi}$ \\
\hline 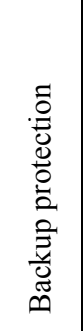 & 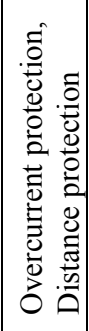 & \multicolumn{2}{|c|}{$\begin{array}{l}\text { Multiparameter relative } \\
\text { selectivity protection }\end{array}$} & 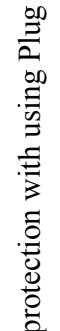 & 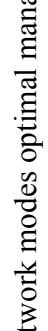 \\
\hline 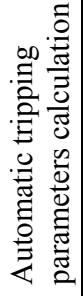 & N/A & $\begin{array}{l}\text { Protection se } \\
\text { calculation }\end{array}$ & tings automatic & 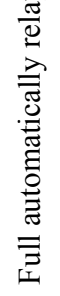 & 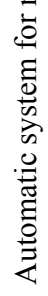 \\
\hline
\end{tabular}

\section{Conclusion}

In the course of research, we have developed a prototype of a highly sensitive intelligent relay protection system for electric field circuits and conducted:

- a scientific and engineering applicability analysis of modern relay protection types in prospective $6-35 \mathrm{kV}$ field circuits;

- an engineering analysis of the new highly sensitive multidimensional relay protection triggers; 
- an engineering technical perfection analysis of a fundamentally new current protection for a purely emergency mode;

- we developed an interaction scheme between existing and prospective relay protection types to increase the protection sensitivity and speed of digital field circuits;

- we developed the main stages and methods of introducing relay protection new types;

- we developed a automatic adaptation version of tripping parameters for multidimensional intelligent relay protection devices of electric field circuits running based on the "conventional settings" method;

- we created a method and an algorithm for automatic settings (tripping parameters) calculation for relay protections depending on the actual configuration of an electric power network;

- we have created a prototype of software for digital simulation of operation modes.

\section{References}

1. S. Chowdhury, S. Chowdhury, P. Crossley, IET RENEW Energy Series J. 6, 297 (2009).

2. M. Dewadasa, R. Majumder, A. Ghosh, G. Ledwich, ICPS '09, 1-6 (2009).

3. H. Nikkhajoei, R. Lasseter, IEEE Power Engineering Society General Meeting J., 1-6, (2007).

4. A. Kulikov, M. Sharygin, Power Technology and Engineering J., 3, 37-46 (2018).

5. A. Kulikov, M. Sharygin, Electrichestvo, 7, 20-29 (2017).

6. M. Sharygin, V. Vukolov, A. Petrov, E3S Web of Conf. 139, 01048 (RSES 2019).

7. W. Najy, H. Zeineldin, W. Woon, IEEE Transaction on Industrial Electronics, 4(60), 1668-1677 (2013).

8. A. Kulikov, D. Bezdushniy, M. Sharygin, V. Osokin, E3S Web Conf. 139, 01040 (RSES 2019).

9. M. Dewadasa, A. Ghosh, G. Ledwich, IECON-2011, 37 (2011).

10. X. Kang, C. Nuworklo, B. Tekpeti, M. Kheshti, J., Journal of Engineering, 13(2017), 1515-1518 (2017). 